\title{
The T-shaped Engineer: Connecting the STEM to the TOP
}

\section{Prof. Joe Tranquillo, Bucknell University}

Joe Tranquillo was the second faculty member in the new Biomedical Engineering Program at Bucknell University and helped build an accredited department with seven faculty and 60 undergraduate students. His teaching interests are in biomedical signals and systems, neural and cardiac electrophysiology, and medical device design. Nationally Tranquillo has published or presented over 50 peer reviewed or invited works in the field of engineering education. In 2012 he was a founding faculty member of the KEEN Winter Interdisciplinary Design Experience and a core faculty member in the Institute for Leadership in Technology and Management at Bucknell. He was the founder and inaugural chair of the Undergraduate Research Track at the Biomedical Engineering Society (BMES) conference, and co-organized the Biomedical Engineering Body-Of-Knowledge Summit. He served on the board of the Biomedical Engineering Division of the American Society of Engineering Education (ASEE) and was elected as chair of the division in 2012. He is the winner of the 2010 National ASEE Biomedical Engineering Teaching Award and in 2011 was selected to be a National Academy of Engineering Frontiers of Engineering Education faculty member. 


\section{The T-shaped Engineer: Connecting the STEM to the TOP}

\section{Introduction}

There is an ongoing movement to educate T-shaped engineers, those with technical depth (STEM) as well as cross-disciplinary breadth (TOP). However, most engineering curricula compartmentalize the depth and breadth into different classes. The result is that our graduates are not T-shaped, but are better characterized as two disjoined lines. In this paper I will argue that in order for students to make the connection, individual courses should create environments where students can practice joining the two lines into a $\mathrm{T}$.

Although simple to state, there are two barriers that prevent faculty from delivering what I will call "T-shaped courses." The first barrier is the perception that technical content must come first and there is no practical way to include the T-shape. In the first section, I will highlight two curricular case studies (Creswell, 2013) that demonstrate how breadth can in fact strengthen technical depth. The second barrier is ideological - that the T-shape is not important either to an individual or to society. In this second section, I will review the literature, provide common arguments against the $\mathrm{T}$-shape, and then offer a rational why all engineers should be T-shaped. Given the makeup of the ASEE community, these philosophical arguments may be preaching to the choir. But I hope these arguments will serve the purpose of answering the questions that will be asked (from students or administrators) of any instructor who implements a T-shaped course.

\section{Section 1: Practical Barriers}

Creating a T-shaped course comes with many practical hurdles; there is pressure from post-graduate needs, ABET requirements, departmental and institutional requirements, and even the politics of faculty load allocation. But, in the spirit of engineering design, constraints are always present and can in fact aid in the development of a T-shaped course. As examples, I will provide details on two courses that were offered in at Bucknell University in Fall 2012: a required signals and systems course, driven by the design of biomusical instruments; and a technical elective co-taught with a professor of comparative humanities. Although student data were collected and were overwhelmingly positive, the numbers are not the point of this paper.

Woven throughout the cases are two categories of observations. First are stories of how students not only formed $\mathrm{T}$-shapes but began to have genuine interest and engagement in another discipline. The second class of observations are operational and aim to help others implement similar courses. The section is concluded with unexpected outcomes and ideas for how to introduce the a lower case ' $t$ ' - short experiences that can be embedded within traditional courses.

\section{Extreme Problem Based Learning - Building Biomusical Instruments}

A traditional signals and systems class will focus on topics such as Laplace transforms, feedback control, data acquisition and signal processing. More enlightened courses include labs or long-term projects that challenge students to connect theory to design (Tranquillo, 2007). But one way to create a T-shaped course is to challenge engineers to 
apply their skills outside of traditional boundaries. With that goal, I challenged my BMEG 350 (junior-level biomedical engineering) students to design and build nontraditional musical instruments.

Each student team designed and constructed an instrument that would record biological signals and then transform those signals to Musical Instrument Digital Interface (MIDI) code, a protocol that simulates the sounds of standard instruments. The MIDI code could be streamed through a software library and out to the computer sound card. The system was required to work in real-time and no prerecorded sounds were allowed, enabling a musician to freely improvise. Most importantly, a New York jazz musician, turned clinical professor of music, visited the class on several occasions with his improv students. The trained musicians acted as end users and clients. They made suggestions throughout the semester and pushed the engineering students in new directions, often teaching them a good deal of music theory in the process.

\section{Course Structure and Assignments}

Students still learned the topics of a more traditional signals and systems course through readings, homework and weekly quizzes (Tranquillo, 2007). But much of the material was delivered just-in-time to individual groups. A series of 12 custom-made LabView exercises led student teams through the basics of graphical programming (LabView, National Instruments) and Data Acquisition (DAQ). Several of the labs also built in learning MIDI. An individual lab practicum, focusing on both hardware and software, was administered toward the end of the term to ensure that teams did not specialize too much.

The biomusic project was layered on top of the traditional course material through seven project assignments. At the end of the second week, student teams submitted abstracts with ideas for three possible instruments. After the first month they were required to narrow their scope to one instrument and submit a written proposal. Two months in, a feasibility demo was required along with a revised proposal. Each of these assignments was followed up with an instructor meeting. Throughout the semester, students were required to document their process on a website that was evaluated at the middle and end of the term. The last assignments were a final demonstration and a final write up. In a typical week, four out of the five classroom hours were used for hands on labs and project time.

At the end of the semester, there were some impressive successes. For example, student teams designed and built instruments such as an instrumented glove to capture and manipulate vocal sounds, an organ that responded to skin conductance, and a series of 6axis force plates that generated sound based upon a combination of forces and moments.

Student Learning and Motivation

All well executed Problem Based Learning (PBL) courses set the stage for deep learning (Prince, 2004). Technically the biomusic project was driven by what is known as a "wicked" problem - one that, given the current students' skillset, appears nearly impossible to tackle. The biomusic project was wicked in that all devices were driven by 
biological signals that contain delays, drift, and sensitivity to electrode application. To overcome these problems, students needed to use the theory they were learning. They also learned to reframe problems - for example one group made a breakthrough when they redefined their system as human-instrument, rather than two separate systems.

PBL-type courses also allow students to confront real-world non-technical problems such as managing projects and documenting progress. Each group managed a website where they documented their progress and used post-its to track action items.

The biomusic project, however, was wicked in another way. There were real constraints coming from multiple sources. Some constraints were internal and of a logistical or technical nature (e.g. assignment deadlines, requirement of real-time function, MIDI standard). Other constraints were inherited from another discipline. For example, the class quickly realized that having all percussive, or all high-pitched instruments would not enable mixing sounds. This was striking because I placed no requirement that the instruments be played together. They also recognized the need to select and stick to a series of notes (a scale). After calling a class meeting, they decided to put the question to their users. The jazz students were invited to suggest a scale and give input on the instrument voicings. Similarly, student requested workshops on brainstorming (De Bono's Provocation and Six Hats), improvisation (verbal, musical and movement) a mini-workshop on stage presence (guest speaker from the Dance Deparment at Bucknell).

Individual groups reached out to non-engineering experts. The group that worked on the musical glove, reached out to the costume department, and all members of the team learned to sew. The group that created the galvaonic skin organ were in regular contact with the psychology department. One group seriously considered controlling stage lighting with biological signals. Although they abandoned the idea, they had conversations with the lighting director in the theater department. They came back from these meetings amazed by both the breadth and depth of knowledge of the lighting director, and in particular that he spoke a closely related dialect of the systems language they were learning. After that group told the story to the class, the students asked if there was anyone in the theater who worked in audio. The following week the class had a guided tour of the theater with the audio engineer.

The dynamics of the class encouraged cooperative groups to form. For example, many teams found it most efficient to have one team member focus on the Graphical Programming in Labview, another on the MIDI standard, and another on the sensors in the system. There were a number of ad-hoc meetings where, for example, the programming experts from different teams would periodically meet to share what they had discovered.

The class format and project also created some natural bridges to topics that are notoriously uninteresting to students. The importance of industry standards, even in the context of capstone design courses, is certainly one of those topics. In the biomusic project, the MIDI standard fell naturally out of the scope of the project. But another surprising connection came from a question about how the LabView program mapped 
keyboard strokes to numbers, and why it was the same mapping on Macs and PCs. This was a classic case (many that occurred during the program) where I did not know the answer. I mentioned that there was likely a standard keyboard layout mapping that was being exploited by the program. After five minutes of searching, one student found the standard (ISO/IEC 995). This is one of many such stories where a surprise in the project led to student tracking down an answer.

Another aspect of the course was that students actively were on the look-out for nontraditional instruments. They initially brought up the Theremin, TalkBox (most popularly used in Bon Jovi's 'Livin' on a Prayer"), John Cage's Prepared Piano, and the Drumitar/Zendrum (an electronic percussion instrument played by Future Man of Bela Fleck and the Flecktones). But during the course they discovered many more, ranging from Music from Neurons (Lab of Alain Destexhe) to a technical paper on music from biology (Brouse et al., 2005) to the Landfill Orchestra (music created from garbage in Paraguay). And even after the class was over, students have continued to send me information. In fact, in December 2012, I received two links from a former student - a performance by the classically trained musician turned electronic artist, M4S0N1C, playing two Novation Launchpads and a TED Talk of Bobbi McFerrin "playing the audience."

At the beginning of the class, the intention was for the engineering students to build the instruments and deliver them to the musicians, as in a standard client-engineer relationship. As the semester progressed, the students and musicians formed a real partnership and asked for a public performance/demonstration of the devices at the end of the semester. It turned out that another collaboration was occurring between a dance class and sculpture class, where the sculpture class was creating wearable sculptures that restricted the movements of the dancers. The four classes joined forces to put on a joint performance in May in the student center.

Perhaps most telling, however, was that as the performance date approached, the engineering students asked if they could play their own instruments, as they had become very good at playing them. During the performance, the engineers confidently performed alongside the music students. You may find out more information on the performance at: http://bucknellinnovationgroup.blogs.bucknell.edu/2012/04/20/impulse-group-and-the-dense-network/

\section{Instructor Observations: Pain and Passion Points}

I have taught a project-based version of the signals and systems course for 6 years, focusing on medical device design (Tranquillo, 2007). I can confidently say that the music project brought the theoretical concepts alive in a way that the previous medical device project did not. While the medical device design project provided opportunities to apply some small bits of the signals and systems domain, the music project generated a more holistic technical experience.

In choosing a project to tackle, I was opportunistic. I had worked with the jazz professor before and had informally polled the students before the course. In fact, I had several possible projects in mind, including training rats to detect landmines (in collaboration with a psychology professor), and athletic rehab equipment (in collaboration with the 
athletic department). But in my polling I found that nearly everyone in the class has some musical training, and a few were nearly at the level of the music students. What the experience highlighted was that it pays to play to the passions of the students. It is from these passions that an instructor can not only engage students in the material but also help them to internalize why the T-shape matters.

Passion points often have some built-in hooks to the subject matter. For example, the music project naturally highlighted the Fourier Transform, and the often nebulous connection between delays, eigen values, time constants and poles of a system. In some cases (especially in smaller classes) it is possible to find one project that resonates with nearly everyone. Finding these passions and amplifing them through the material of the course is one pathway to building a strong $\mathrm{T}$ junction. In other words, many student passions come from the TOP, which can then be amplified by the STEM. In future years I could image the passion points coming from relationships with younger siblings or cousins, athletics, social justice / civic engagement or entrepreneurship.

The course was certainly a joy to teach but was far from straightforward. There were many more logistics to clear the path for student success. As in any PBL courses, I needed to play a role closer to that of a coach - using praise when groups were trying but frustrated, but also honest feedback when groups were coasting or making excuses.

I hope that the picture I have painted is of a course that was unique and rich with learning opportunities, and that criss-crossed from the technical to the non-technical many times. But one more aspect was critical - reflection. Every two weeks, the I conducted a short reflection meeting with the students. The goal was to extract lessons learned. Some were individual, private and more formal, while others were informal public discussions. In course evaluations, students shared that it was during these reflection periods that the light bulbs went off.

\section{Radical Disciplinary Mixing - Brain, Mind and Culture}

Engineers typically take some number of courses outside of the sciences to fulfill university and ABET breadth requirements. Unfortunately, while they typically perform well, many engineering students do not take these courses seriously. They put on their humanities and social science "hats" on in these courses, but then quickly take them off again once they are back to their engineering life. Those who do gain some lasting insights keep them compartmentalized.

The Brain, Mind and Culture course was co-taught by the author and a professor of comparative humanities. It was cross-listed in the departments of biomedical engineering, neuroscience and comparative humanities, with student enrollment from all divisions of the university. The course objective was to provide a venue for an intellectually diverse group of students (including engineers) to compare and contrast their different methods, traditions, communication styles, and hot-button issues.

Pedagogically, the course was driven by readings included historical and contemporary philosophy (Clark and Chalmers 1998, Hume 1748, Levy 2007), science (Henrich et al., 
2010, Gazzaniga 2011, Edelson, 2012), engineering design (Robotic Surgery, Oxman 2006, and Oxman 2010), film (Headless Woman, Casino Royal, Wesch's The Machine is Us/ing Us), art (Orlan, Stelarc) and local and international news. Content was chosen to give concrete examples of methodology and tools from a variety of disciplines. When possible, the same topic (e.g. feminist theory; Fine, 2011, Berenbaum et al., 2007) was approach from multiple viewpoints (e.g. genetic, psychological, sociological, philosophical). Class time was used for semi-structured, students-led discussion on the readings. The first 10-15 minutes of each class were reserved for clarification. It was during this time that definitions, methodology and discipline-specific history were shared. Often the students took the lead on answering questions.

As the course was cross-listed in biomedical engineering and neuroscience, technical content was required. An extra hour was offered during which a number of topics were introduced that are often skipped in more traditional engineering and neuroscience curricula: agent based models, game theory, non-linear dynamics, network/graph theory, open systems and self-organized criticality. All technical sessions were connected to the main class topics. Many of the humanities students, who were not required to attend the fourth hour, participated anyway.

All students were required to complete an individual, semester-long project using the style of a discipline different from their own. The bounds of the project were left open, and the instructors worked with each student to find a project that allowed them to practice making their own T-shape. For example, one engineering student analyzed the tension between the administration and the Greek system through the lens of game theory and network science. This particular student came out of the project with a new-found appreciation for the position of the administration. Another student combined her love of bike racing with principles from self-organizing systems. In a few cases, however, an engineering student adopted a methodology from outside of their discipline. In one wonderful example, an international engineering student, working with a professor of English, learned how to conduct Grounded Theory research (a flavor of qualitative research). In her final presentation, she expressed how surprised she was to find that a "qualitative method" could be even more rigorous and difficult than her quantitative engineering work.

\section{Student Learning}

The focus of the course was for students to see their own discipline as not ending at the boundaries of their curriculum. By being able to compare and discuss different disciplines side-by-side, many students became more aware of why their discipline asks certain questions, the acceptable form of answers and the assumptions that are hidden inside of these question/answer pairs. Toward the end of the class, many students began to express openly what they thought was missing from their own discipline as well as what their discipline might have to offer to other disciplines.

The class studied the work of Neri Oxman, a visionary architect and material scientist at the MIT Media Lab, who has advocated for a new type of design using the selforganization of materials. It is design in reverse, where the designer creates the rules for 
how materials will combine, but then lets the materials optimize the structure. This approach was quite a shock to many of the engineers who were currently deep into a formal design process in their senior capstone. But, it was clear that the possibilities were not quiet hitting home. So the class watched as a 3D printer rendered one of Oxman's design during a discussion. That discussion was followed up by a second article by Oxman where she predicts that someday entire buildings will be "printed" from simple rules, and that these buildings would not only be optimized to their environment, but also adapt when the environment changed.

The course was divided into four units, with each unit focusing on a wider theme (e.g. Histories of [Neuro]Science, The Body and Mind as Open Systems, Transformation of Learning and Social Interactions). At the end of each unit, students had the opportunity to add extra content to the unit. In this way, students were co-creators of the course. Sometimes they brought in readings from other classes. Other times they shared stories from extra-curricular activities. The emphasis was placed not on the material but on the active search for connections across disciplines. In fact, one of the students proposed for the class to watch the South Park episode, "Fish Sticks" (Season 13, Episode 5), as a follow-up for our discussion on memory. In the episode, the character Cartman replays an incident in his head over and over again, making it more and more outlandish, until at the end of the episode he believes his self-constructed lie so strongly that he is willing to die for it. After some debate between the two faculty, we decided that the student did have a good rational and that the connection to the class material was strong. The viewing led to a very rich discussion and I realized that if students could see their course material coming alive in an episode of South Park, the course was having the intended impact.

\section{Team Teaching}

Team Teaching can be a powerful way to create a T-shaped course, but it is not for the faint of heart. Unlike single-instructor courses, decisions require discussion: student recruitment, course content and structure, syllabus and website, readings and assignments, grades, office hours, and in-class work. How should the workload be distributed? How will all of the small decisions (e.g. extensions, in-class surprises) be made? There are many models, ranging from everyone doing everything to complete divide and conquer. No matter the model, team-taught courses are more work.

The weight of these decisions is amplified when two cultures collide. The waves that are created feel uncomfortable, even to the instructors. How much should ideas be held in tension? Is it better to have a linear or non-linear flow to the class? Will the course be about questions or tools or methodologies? On top of these content collisions, students and faculty from different disciplines carry with them assumptions about the rhythm of a semester. These are just a sampling of the questions that need to be addressed and communicated to the students.

Team teaching across disciplines is certainly not new and most institutions have at least some radically interdisciplinary classes. Perhaps no school has embraced it as fully as Colorado College. The book Co-teaching That Works (Beninghof, 2012) is a nice summary of years of expertise. Based upon the finding at Colorado College and my own 
experiences, there are some helpful hints. Expect the classroom environment to at times be off balance. For example, when the class discussed Hume, some felt right at home while others were out of their element. As an engineering professor, I would often play the role of asking the "silly", but very genuine, questions of a novice. In a class with interdisciplinary topics and students, it is hugely valuable to have someone playing this role.

In a mixed discipline class, some explanation of disciplinary grounding will be necessary. In Brain Mind and Culture, students practiced expressing the accepted views of their discipline. Some students found that they held an incorrect view of some aspect of their own discipline. For most, this was a welcomed experience. A few students expressed the accepted view of their discipline but then followed it up with what they personally thought of that view. Again, these were enlightening experiences that were mined for learning. Lastly, the faculty did their best to be role models - to respectfully disagree, learn along with the students, and give them an example of what a T-shaped person looks like.

Wandering off topic during an interdisciplinary class is very easy to do. Students, and even faculty, are vying to get onto familiar turf. This multi-directional pull can easily lead to parts unknown. It is often during these times that deep connections are made and light bulbs come on. But, there needs to be some recognized way to get back on track. In the Brain, Mind and Culture class, this became eye contact and a nod between the instructors.

Above all, the key elements to build into the classroom are trust and respect. There will be moments when one discipline will shine. At other times that same discipline will appear terribly short-sighted. It is through trust and respect that the class can paradoxically be both critical and accepting.

\section{The Value Beyond the Primary Objectives}

In this section I will explore some secondary reasons why a faculty member might invest time and energy in creating T-shaped experiences.

\section{$\underline{\text { Student Rewards }}$}

Students enjoy new and unrepeatable experiences. Students know that if they really need signals and systems content for their job 10 years from now, they can learn it. What they cannot recapture is the experience of the course, such as building a biomusical instrument. This sense of urgency and immersion generates very rich and very deep learning moments.

The emotionally charged pathway of a T-shaped experience also creates unique stories. Many students, in both classes, have mentioned that they referred to the course in interviews, most often in response to the classic question: "Tell me about a challenge and how you overcame it." Students can also highlight their ability to do something truly novel. The team working on the biomusical gloves have a particularly powerful story. During their research they found a TED talk by the avant-garde pop musician Imogene Heap, who has been working with Virtual Gloves that sample, filter and play back her 
voice. Their reaction when they discovered her work was "we've done that." While their product was clearly not as sophisticated, they saw that with time and resources they could build something comparable (Heap, 2011).

The T-shape of a course can help students parse the formal learning objectives of the course. For many years, I have posted learning objectives, explained Bloom's Taxonomy and done my best to map the activities of the course to the objectives. What I heard back from some students, however, was that learning objectives were too abstract and they only looked at them around test time. In the T-shaped experiences described, I turned the tables and challenged students to let me know when they saw an opportunity to focus on an objective. The result was that they were in charge of not only knowing the objectives, but being actively on the look-out for ways to show me how they were meeting them.

\section{Faculty Rewards}

There are some very concrete ways in which faculty benefit from providing T-shaped experiences. Although raw teaching scores may not go up, the written comments clearly justify the pedagogical approach. It was noticed by my department chair that students characterized both classes as transformative experiences. In this way, T-shaped courses are quickly noticed by students and administrators. University alumni in particular see the merit, and view this type of training as something that makes their alma mater special. For that reason, these activities can become great show pieces for the administration. Both the biomusic project and Brain Mind Culture class have been featured in University-level publications.

In the process of building a T-shaped experience, faculty may also find others at their institution who wish to collaborate on an unusual project. For example, through our regular contact in the Brain, Mind and Culture class, the comparative humanities professor and I co-authored two conference publications (Tranquillo and Hunter 2011, Hunter and Tranquillo 2012) and were featured in a CNN Health article (Landau, 2012). As a result of another class (not discussed here), I collaborated with a professor of psychology. The outcome was an STTR grant with a defense contractor, and an upcoming program on the Discovery Channel. Again, these unique experiences brought me much more attention than my traditional research program.

Lastly, faculty often would like to pursue a project that does not fit neatly into any current research thread. Matching students to these exploratory projects is particularly difficult. The unusual classes described proved to be very helpful in finding students willing and able to take on a new research direction.

\section{Lower-case $t$}

The two courses show variations in how a fully formed capital $\mathrm{T}$ can be encouraged. But it is often not possible, or unreasonable, to offer classes in this way. In fact, the Brain, Mind and Culture class required nearly five years of red tape to be lifted. As an alternative, there are some simple ways that engineers can get bits of the TOP inside of more traditional courses; what I will call the "lower-case t." Many instructors already bring in current events and stories from their own experiences. What can be added to 
these ad-hoc approaches is more intention. By explaining why and how the stories extend beyond the classroom material, you send the signal that cross disciplinary connections are a valued outcome of the class. Below are ideas on being more intentional.

I often look at the bubble around my discipline. Reading current events can help, but I have also found lunch with colleagues a deeper source for T-shape content. As I discover connections I bring them into the classroom and share how I discovered them.

In the past, I invited guest speakers who were experts in a sub-field of the class material. For example, I have invited a speech signal processing expert to give a talk in my signals and systems course. Though no fault of his own, his research talk added little value. Where I have found invited talks to add value is when the talk brings an unexpected twist to the course. Most often these topics are in the bubble around the discipline. I have found that a meeting with the speaker ahead of time can clarify this objective. A similar type of experience can come from campus or regional events. In this case, it will be up to the students to look for the T-shape in the event.

A combination of readings and discussion can also be very powerful. I have offered a neural signals and systems elective for several years. The traditional classroom time focuses on the biophysics of ion channels, action potentials, propagation and small neural circuits. A discussion period moves to the opposite end of the spectrum, driven by reading from Dennett (2001), Kurzwiel (2000), Martin Luther, Eramus and Ramon y Cajal, as well as many of the sources from the Brain Mind and Culture class. What students gain from this approach is a recognition of the gaps between our scientific understanding of the brain and the philosophical questions surrounding minds.

\section{Section 2: Ideological Barriers}

Steve Jobs famously stood beneath a giant street sign showing the intersection of technology and the liberal arts (Jobs, 2011). He explained that this was where innovation happens at Apple. The value of this intersection is not a new idea; T-shape is simply the latest incarnation. In this section, I review the history of the T-shape and point out the two major criticisms of teaching the T-shape to university level students. I will then given my own answer to these critiques with the goal of arming the reader with answers to students or administrators who might question the importance of teaching the T-shape.

\section{History of the T-shape}

The idea of the T-shape clearly goes back a long way, but it was in the early 1990s that it took on the meaning used throughout this paper. Colin Palmer published research for the British Computer Society discussing the need for "hybrid" managers in the technology world (Palmer, 1990). Palmer acknowledges that the term "hybrid" was coined by Michael Earl at Templeton College, Oxford. The following year David Guest wrote an editorial for The Independent (London), based upon Palmer's study, where the first mention of the T-shape appears: 
This type of rounded personality is also sought in other branches of the same theory, which prizes individuals known as T-shaped People. These are a variation on Renaissance Man, equally comfortable with information systems, modern management techniques and the 12-tone scale.

A number of high profile thought leaders have advocated teaching and hiring T-shaped people, including Tim Brown at IDEO (Hansen, 2010) and Jim Spohrer at IBM (Donofrio, Sanchez, Spohrer, 2009; Donofrio, Spohrer, Zadeh, 2009). The T-shape has been publicly acknowledged as part of the DNA of several high profile companies, including Toyota, Apple and Google. This idea from the technology world has been adopted by marketing and management (Hansen, Oetinger, 2001; Appelo, 2010, Rust, Moorman, Bhalla, 2010), the medical profession (Donofrio, Spohrer, Zadeh, 2009) and even philanthropy (Stannard-Stockton, 2012). In one of the few empirical studies of the T-shape, a wide survey of job descriptions over the last several decades showed a rise in the need for expert thinking combined with cross-functional communication (Levy and Murnane, 2004).

Largely driven by industrial and professional hiring, the university education world has adopted the T-shape. For many engineering programs, the T-shape aligns nicely with their interpretation of the ABET phrase "life-long learner" (Criteria 3i). MIT and Stanford have both published high profile articles (Matcho, 2011; McMaster, 2012), and the US government has recently begun to fund centers that facilitate the spread of some key aspects of the T-shape (e.g. Engineering Pathways to Innovation based at Stanford). And the US is certainly not the only country seeking to educate T-shaped professionals (Oskam, 2009; Wu and Zou, Kong, 2012; Skyrme, 2013).

Gardner has published on nurturing young T-shaped professionals (Gardner, 2011), and a forthcoming book "Model T - how to create T-shaped professionals," although written for companies, may provide some valuable insights for college educators. Lastly, the Tshape movement has joined with some bold calls for reform - most especially for holistic engineering education (Bordogna, Fromm, Ernst, 1995; Donofrio, Sanchez, Spohrer, 2009). The goal of these reforms is to educate a new-age Renaissance Man [Woman] who will spark a period of intense innovation - what has been dubbed the "Medici Effect" (Johansson, 2006).

There is no common definition of the T-shape. To some, the TOP of the T originates within in a very particular discipline, for example marketing, management or entrepreneurship (Morello, 2005; Oskam, 2009; Wu and Zou, Kong, 2012; Skyrme, 2013). Here the TOP is composed of the skills and thought processes from a particular discipline. At the opposite end of the spectrum are those who advocate superimposing a technical background onto liberal arts training (Jobs, 2011) - to adopt a T-mindset (what I have here called the growth mindset). The T-shape also goes by some aliases, including "Generalizing Specialist" (Appelo, 2010), "Hybrids"(Palmer, 1990), and "Versatilist" (Morelo, 2005). 


\section{Arguments Against the T-shape}

Perhaps the most common argument against the T-shape is that it will stunt the learning of depth in a discipline. As the case studies above demonstrate, this is not necessarily the case. I will therefore focus here on two deeper arguments against the T-shape. On the level of an individual, perhaps the T-shape cannot be taught. Or maybe it can be taught but the 18-22 year demographic is not the right target. If that is true, should the seeds should be planted earlier (K-12 education)? Or maybe a true T-shape only be learned after college. These types of questions (especially in the absence of clear answers) can become barriers to adopting the T-shape.

Even if teaching the T-shape to college students is beneficial to an individual, there are some socioeconomic reasons why it may not make sense. One very important function of T-shaped workers is that they allow knowledge to flow efficiently through an organization, often across traditional boundaries. But the question is how many T-shaped people does it take? Is it best for everyone to be T-shaped? Or perhaps is there a saturation point after which adding more T-shaped people does little for, or maybe even harms, a company. This idea has been studied through computer simulations (Cataldo, Carley, Argote, 2001). An economic argument can also be made that the return on educating a T-shaped person is not worth the gain, both for a university and for the market that hires graduates (Donofrio, Spohrer, Zadeh, 2009).

It is also not clear if the T-shape is the right shape (Buxton, 2009). For example, Leonard-Barton discusses "A-shaped" (sometimes also called " $\pi$-shaped") people (Leonard-Barton, 1995) - those with depth in more than one discipline. They are truly bilingual and can connect two groups together more tightly than a T-shaped person. The "I-shape" (for Innovation) is sometimes used to mean professionals who have their feet planted firmly on the details of their discipline but can from time to time come up to look around. Still others advocate the traditional "STEM shape", as being successful in the majority of work environments (Buxton, 2009).

\section{Addressing Arguments Against the T-shape}

Based upon my own experiences and what I perceive to be most relevant to the reader, I have focused below on addressing the pedagogical rather than the social value. To this latter criticism, I would simply respond that it is based upon the flawed assumption that depth must come as the expense of breadth.

The question I will respond to is: "What, if any, value is there in T-shaped undergraduate courses and curricula?" Many students have began to form a T-shape before college and will continue to become more T-shaped over time. But it is that during the undergraduate years that students will transform their various interests into a mindset that will guide them throughout their career. Teaching the T-shape also brings natural contact with the messiness of the real world, and therefore exercises the capacity for complex thinking. I will use the two words mindset and real world to focus the discussion below. 
The Growth Mindset

A mindset is lens through which the world is viewed. It is a very complex psychological object and can only be learned through a process of self-discovery. Here the undergraduate brain is at the perfect intersection of two competing phases of development. Neuroscience and psychology have shown that the 20 -something brain is still developing. At the same time, years of wrestling with more and more abstract concepts has primed the brain to handle the complexity of learning a mindset (How People Learn, 2000). Undergraduates, with some prompting, are able to take concrete experiences, and not only abstract them, but include them into their views of the world. It is very exciting to work with people during this period of their lives.

One mindset in particular appears over and over again as the key to long-term fulfillment and success. Stanford psychologist Carol Dweck has contrasted the fixed mindset with the growth mindset (Dweck, 2006). In the fixed mindset, "an individual believes that their qualities are carved in stone." This "creates an urgency to prove oneself over and over again." The important questions for those with the fixed mindset are: "Will I succeed or fail? Will I look smart or dumb? Will I be accepted or rejected? Will I win or lose?"A person with the growth mindset, however, believes that their "basic qualities are things that they can cultivate through effort." They ask, "What have I learned? What can I do next? Where can I have an impact?"

Students with either mindset can achieve, but do so for very different reasons. The fixed mindsetters achieve because they have explicit goals that will be either met or not. Meeting the goal is defined as success, while not meeting the goal is the very definition of failure. The growth mindsetters, are learning focused. For them, failure to meet a goal can still be a success if something was learned. Dweck has extended the idea to everything from business to personal relationships. She has argued very persuasively that short-term success may be gained through the fixed mindset, but that the pathway to lifetime success, and personal fulfillment, is through the growth mindset. Furthermore, Dweck emphasizes the fact that the growth mindset can be learned through repeated reinforcement. It is like a muscle to be exercised.

So how can an environment be constructed in which students adopt the growth mindset? It is not easy to take the focus off the grades and put it on learning - grades have led them this far and they are perceived as the path to future success. But grades are part of the fixed mindset, while learning is the domain of the growth mindset (Baim, 2004). Because $\mathrm{T}$-shaped experiences have many pathways to any number of goals, they do not have black and white wins and losses, and instructors can reward growth rather than getting the right answer. The pathway to receiving a good grade is directly connected to demonstrating that learning has taken place.

Adopting a growth mindset is catalyzed in an immersive environment. Based on some recent neurosciencentific findings (Demasio 2005, LeDoux, 2003), immersive, trial-byfire experiences bring about intense emotional responses. And it is an emotional response that allows learning, including learning a mindset, to stick. T-shaped experiences are breeding grounds for sticky learning (Heath and Heath 2009) because they are so 
emotionally charged. The biomusical project was immersive in that it dominated student time both in and out of the classroom. The Brain Mind and Culture class was immersive in that studets were encouraged to look outside of the class for sources of inspiration.

The third component of a T-shaped environment is the opportunity for reflection. As opposed to content-based courses, where the focus is on mastering material, a T-shaped course can strengthen connections. In content-based courses, reflection often takes the form of a one-page assignment at the end of the class. What students most often produce is a summary of the content they have learned along with a surface level assessment of where they might use the information in the future.

I have been developing tool, called the Reflection Ladder (Figure 1), that is loosely based upon Bloom's Taxonomy and is used throughout the semester. It is another instructiona tool to encourage the growth mindset. The higher a student climbs on the Ladder, the better they can see where they have been, where they are and where they might go next. The goal is for students to progress in their reflection skills throughout the semester. Throughout the biomusic course I designed reflective experiences (group and individual as well as written, verbal and graphical) that helped students practice their reflective abilities.

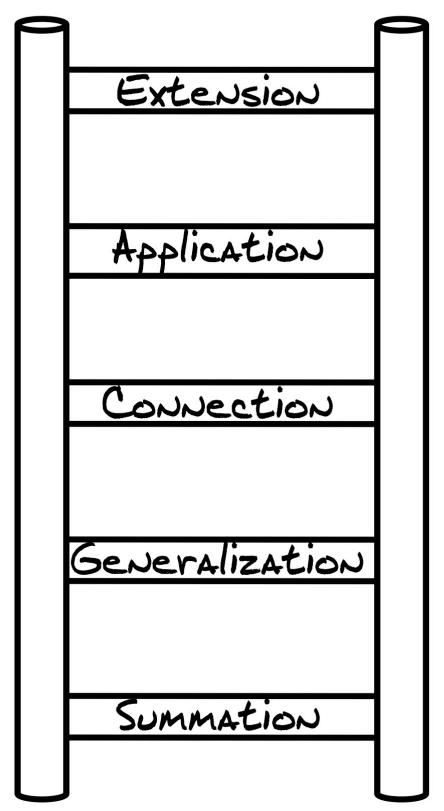

Describe another current or future situation that you anticipate will involve the same broad concept. What is one concrete step you can take to apply the concept that was reinforced during this experience?

Knowing what you know now, what would you have done differently given the same circumstances?

How did the experience reinforce the broad concept?

Describe the broader concept that the experience highlighted. Why is this concept important?

Describe the experience (who, what, where, how, why). Make sure to address "why" as this is often the most neglected aspect.

Figure 1: Reflection Ladder, used as an aid to improve the depth of reflection.

\section{Real-World Challenges}

What is so powerful about bringing the real world into the classroom? Faculty may answer that is that it is practice for future careers. Students would agree that real world problems are and exciting taste of what they will encounter at the end of their formal education. But there is a deeper philosophical reason that dove-tails with the growth mindset; encounters with the real world build the capacity to simultaneously hold many interlocking ideas in one's mind. 
Complex real-world problems, sometimes called Wicked Problems, are really multi-level problems. To generate a true solution requires addressing the issues at all levels, from the 50,000 foot (potential for impact) to the 5 foot (implementation). Engineering educators have historically put a lot of emphasis on the 5 foot view, preparing entry-level engineers for their first job. The T-shaped engineer is often sold as having both the depth to handle the 5 foot view and the breadth to understand the social, political and historical context at the 50,000 foot view. What is missing in the disjoined $\mathrm{T}$ is the ability to move fluidly from one level to another.

It is a tall order for an undergraduate to keep all of these levels in their head at once, and that is the point. Exposure to wicked problems increases the capacity to hold complex, and even contradictory, thoughts in ones mind. The studies of Jim Collins on successful companies and C-level employees demonstrates that a key difference between good and great is exactly this capacity (Collins, 2001). T-shaped experiences allow students to grow this capacity and gain gained confidence in their abilities.

Assigning truly open-ended problems is a sort of Ulysses contract for the faculty member; the instructor can no longer give simple answers. As students learn that the professor genuinely doesn't know the answer, they become invested in finding their own answers. To use a business analogy, I encourage students to become their own Chief Learning Officer (CLO). My role then becomes providing the tools, resources and environment (i.e. the marketplace and economy) for them to succeed, essentially the CEO of the class. As my students progress, even that support begins fade away, as they learn to seek out their own resources.

\section{Conclusions}

Plato advocated "cutting nature at its joints, like a good butcher" (Phaedrus). This philosophy has been the driver of our understanding of the world for millennia and has been undeniability successful at taking apart the world. But as the butcher analogy so aptly illustrates, putting the parts back together again cannot proceed by continuing to cut up the world. This is the dilemma faced by the practicing engineer - to put back together, in meaningful ways, the bits that have been taken apart so ably by the scientific method.

Teaching our students to be T-shaped is one possible way for them to more effectively put science back together in ways that benefit society. The problem is that the butcher analogy has infected the educational system (Snow, 1959), so much so that even those who advocate for the T-shape still assume that teaching depth and breadth separately is the only option. But, like the creation of a mechanical ' $T$ ', the largest stress - and therefore the most probable point of failure - is at the junction. This paper provides another option; to create T-shaped courses that focus on the junction.

Given the barriers to creating T-shaped courses, it is not clear what might precipitate a change in engineering curricula. Jonathan Haidt, a professor of moral psychology at the University of Virginia, uses a wonderful analogy to break down the components of change (Haidt, 2006). His analogy is of an elephant (human emotion), its rider (human 
rationality) and the pathway (environments). All three must be in alignment for intentional and sustained change to occur. It is hoped that in this article, I have offered something for the elephant, rider and pathway. But real change will require many more educators to fix, modify and adopt my outline of T-shaped courses. Together we will create the T-shaped engineers that are desperately needed in the $21^{\text {st }}$ century workplace.

\section{References}

Appelo, J. "Management 3.0: Leading Agile Developers, Developing Agile Leaders". Addison-Wesley Professional. 2010.

Baim, K., "What the Best College Teachers Do", Harvard University Press. 2004.

Beninghof, A., "Co-teaching That Works: Structures and Strategies for Maximizing Student Learning" Jossey-Bass 2012.

Berenbaum, S. et al. "Sex Differences in Children's Play" in Sex Differences in the Brain: From Genes to Behavior. Oxford University Press 2007.

Bordogna, J., Fromm, E. and Ernst, E., "An Integrative and Holistic Engineering Education," Journal of Science Education and Technology 4 (3): 191-198. 1995.

Brouse et al. "From Biological Signals to Music", $2^{\text {nd }}$ International Conference on Enactive Interfaces, Italy 2005.

Buxton, B., Innovation Calls for I-Shaped People". Business Week. Insight Section. July 13, 2009.

Cataldo, M., Carley, K. and Argote, L., The Effect of Personnel Selection Schemes on Knowledge Transfer. CASOS Working Paper. 2001.

Christensen, C. “The Innovator's Dilemma”, Revised Edition. Harper Business. 2011.

Clark, A. and Chalmers, D., "The Extended Mind", Reprinted in The Philosopher's Annual vol XXI-1998 (Ridgeview,. 2000).

Collins, J., “Good to Great”, Harper Business, 2001.

Creswell J., "Qualitative Inquiry and Research Design: Choosing among five approaches", $3^{\text {rd }}$ edition. SAGE Publications. 2013.

Demasio, A., “Descarte's Error” Penguin Books 2005.

Dennett, D., "Where am I?", in The Minds I, Basic Books, 2001. (also online at http://www.newbanner.com/SecHumSCM/WhereAmI.html

Destexhe, A., "Neuronal Music" http://cns.iaf.cnrs-gif.fr/alain_music.html 
Donofrio, N., Spohrer, J. Zadeh, "Research-Driven Medical Education and Practice: A Case for T-shaped Professional”, MJA Viewpoint. 2009.

Donofrio, N., Sanchez C., ,Spohrer J., “Collaborative Innovation and Service Systems: Implications for Institutions and Disciplines", in Holistic Engineering, Edited by Domenico Grasso. Springer. 2009.

D.school (Stanford) Bootleg. 2012 http://dschool.stanford.edu/wpcontent/uploads/2011/03/BootcampBootleg2010v2SLIM.pdf

Dweck, C., "Mindset: The New Psychology of Success”, Random House. 2006.

Edelson, M., et al., "Following the Crowd; Brain Substrates of Long-term Memory Conformity", Science 333(108) 2011.

Fine, C., "Delusions of Gender: How our Minds, Society and Neurosexism Create Difference", W.W. Norton and Co. 2011.

Gardner, P., "Challenges in Nurturing the Growth of Young T-shaped Professional", $2^{\text {nd }}$ International Research Symposium in Service Management 2011.

Gazzaniga, M. "The Way We Are" and "Abandoning Free Will” in Who's in Charge. Ecco Publishing. 2011

Guest, D., "The hunt is on for the Renaissance Man of computing". The Independent (London), September 17, 1991.

Haidt, J., “The Happiness Hypothesis” Basic Books, 2006.

Hansen, M. and Oetinger, B.,'Introducing T-Shaped Managers: Knowledge Management's Next Generation". Harvard Business Review, March Vol 79 No. 4. 2001.

Hansen, T, "IDEO CEO Tim Brown: T-shaped Stars: The Backbone of IDEO's Collaborative Culture", Chief Executive Magazine, January 21, 2010

Heap, I., TEDGlobal Performance 2011 http://www.psfk.com/2011/07/tedglobal-imogen-heaps-musical-gloves-manipulatesound-with-hand-gestures.html. Also see http://imogenheap.com/thegloves/

Heath, C. and Heath D. "Made to Stick: Why some ideas survive and others die", $2^{\text {nd }}$ edition, Random House. 2007. Also see http://www.heathbrothers.com/resources/ for applications to teaching.

Heath, C. and Heath D. "Switch: How to Change Things When Change is Hard", Crown 
Business. 2010.

Henrich et al., "The WEIRDEST People in the World", Behavioral and Brain Science 33. 2010.

"How People Learn: Brain, Mind, Experience and School", National Academies Press, 2000.

Hume, D., "An Enquire Concerning Human Understanding" 1748. Cambridge Univeristy Press 2007 Edition, pp. 14-91.

Hunter, J. and J. Tranquillo, "The Crowdsourced Self". NeuroHumanities Entanglement Conference. 2012. Atlanta, GA

Iansiti, M., "Real world R\&D: Jumping the product generation gap", Harvard Business Review, May-June, pg. 139. 1993.

Jobs, "Technology and the Liberal Arts" 2011

http://www.youtube.com/watch?v=K1I1MR-qNt8

Johansson, F., "Medici Effect: What Elephants and Epidemics can Teach Us About Innovation", Harvard Business Review Press. 2006.

Kurzweil, R., "The Age of Spiritual Machines”, Penguin Books, 2000.

Landfill Orchestra. https://www.youtube.com/embed/7IfmCMTjABk

Landau, E., "So you're a cyborg - now what?", 2012

http://www.cnn.com/2012/05/07/health/memory-computers-brain/index.html

LeDoux, J., "Synaptic Self: How Our Brains Become Who We Are”, Penguin Books 2003.

Leonard-Barton, D., Wellsprings of Knowledge: Building and Sustaining the Sources of Innovation, Harvard Business School Press. 1995.

Levy, F., Murnane, R., "The New Division of Labor: How Computers Are Creating the Next Job Market”. Princeton University Press. 2004

Levy, N., "The Neuroscience of Free-will”, in NeuroEthics, Cambridge University Press, 2007.

M4S0N1C, "Virus" http://www.youtube.com/user/M4S0N1C

Martel, L. (Writer/Director), “The Headless Woman” 2008 
Matcho, M, “A New Start: An Experiment. Learning From Scratch”, Stanford Magazine March 22, 2011.

McFerrin, B., "Bobbi McFerrin Plays the Audience", TED 2009.

http://www.ted.com/talks/lang/en/bobby_mcferrin_hacks_your_brain_with_music.html

McMaster, R., "The T in STEM - The T-shaped Professional”, MIT STEM PALS, June 2012.

Morello, D., "Versatilist: Gartner Says Technical Aptitude No Longer Enough To Secure Future for IT Professionals". Gartner Press Release, 9 November 2005.

NBC News “Device Turns Gesture Into Song” Feb 18, 2012.

http://cosmiclog.nbcnews.com/_news/2012/02/18/10443785-device-turns-gestures-intosong

Orlan, http://www.orlan.eu/

Oskam, I.F., "T-shaped engineers for interdisciplinary innovation: an attractive perspective for young people and a must for innovative organizations." SEFI (European Society of Engineering Education) Annual Conference. 2009.

Oxman, N., "Structuring Materiality: Design Fabrication of Heterogeneous Materials", Architectural Design, 80(4), 2010.

Oxman, R., "Theory and Design in the First Digital Age", Design Studies 27. 2006

Palmer, C., "'Hybrids' - a critical force in the application of information technology in the nineties", Journal of Information Technology, volume 5, pp. 232-235. 1990.

Pink, D., “A Whole New Mind”, Riverhead Trade 2006.

Also see the Discussion Guides at http://www.danpink.com/books/whole-new-mind

Prince, M., "Does Active Learning Work? A Review of the Research", J of Eng Ed. 2004.

Purvis, N., Wade, R. (Screenplay), Campbell (Director), “Casino Royale” 2006

Robotic Surgery http://www.youtube.com/watch?v=n37RiY4CZ_Q

Rust, R., Moorman, C., Bhalla, G., "Rethinking Marketing”, Harvard Business Review, 2010.

Snow, C.P., 1993. The Two Cultures. New York: Cambridge University Press.

Stannard-Stockton, S. “T-Shaped People \& Philanthropy”. Stanford Social Innovation 
Review URL (December 19, 2012): http://csi.gsb.stanford.edu/t-shaped-people-ampphilanthropy

Stelark, http://stelarc.org/?catID $=20247$

Skyrme, D., "Brazil: Develping T-shaped Professionals to Build Knowledge Business Clusters". http://www.entovation.com/gkp/tshaped.htm Accessed January 3, 2013

Tranquillo, J. and Cavanagh, D., "A Project-driven Approach to Biomedical Signals and Systems" ASEE Proceedings 2007.

Tranquillo, J. and J. Hunter, "From the Neural to the Social Networks of Memory; or, 'It's your life crowdsourced'". ThinkArt Conference. 2011 Boston, MA.

Wesch, M., "The Machine is Us/ing Us", http://www.youtube.com/watch?v=NL1GopyXT_g\&feature=relmfu

Wesch, M., "Learning in New Media Environments”, 2009.

http://www.academiccommons.org/commons/essay/knowledgable-knowledge-able

Wu, J., Zou X., and Kong, H., "Cultivating T-shaped Engineers for $21^{\text {st }}$ Century:

Experiences in China" ASEE Proceedings 2012. 